\title{
Patient's early satisfaction with care: a predictor of health-related quality of life change among outpatients with substance dependence
}

Ophélie Müller ${ }^{1}$, Cédric Baumannn ${ }^{2,3}$, Paolo Di Patrizio ${ }^{1}$, Sarah Viennet ${ }^{1}$, Guillaume Vlamynck¹, Laura Collet ${ }^{1}$, Isabelle Clerc-Urmès ${ }^{2}$, Raymund Schwan ${ }^{1}$ and Stéphanie Bourion-Bédès ${ }^{1,3,4^{*}}$

\begin{abstract}
Background: Although research on health-related quality of life (HRQOL) has increased in the addiction field, few studies have focused on the determinants of HRQoL changes. This study aimed to describe dependent patients' HRQoL changes at a 3-month follow-up and to assess whether satisfaction with care can predict those changes among outpatients starting care for alcohol or opioid dependence.
\end{abstract}

Methods: HRQoL was measured with the SF-12 at baseline and 3 months later in a prospective cohort of dependent outpatients. Satisfaction was assessed with the EQS-C early after inclusion. Data on sociodemographics, clinical characteristics and patients' levels of anxiety and depression were also collected. A multivariable analysis was performed to identify factors associated with HRQoL changes in both the physical and mental component summary scores (PCS and MCS, respectively).

Results: Of the 172 patients included at baseline, a total of 136 patients assessed their satisfaction with care. The mean PCS and MCS scores were initially low, and HRQoL improvement was significant after 3 months for both the PCS and MCS. Never having been married $(\beta=5.5 ; p=0.001)$ and a lower baseline PCS score $(\beta=-0.6 ; p<0.0001)$ were associated with significant PCS improvement, whereas being legally compelled to undergo drug treatment $(\beta=-5.9 ; p=0.02)$ was associated with less PCS change. Higher early satisfaction with care $(\beta=0.1 ; p=0.02)$ and a lower baseline MCS score $(\beta=-0.7 ; p<0.0001)$ were associated with significant MCS improvement.

Conclusion: The study supported the hypothesis that greater satisfaction with care may predict HRQOL improvement among dependent outpatients. Further studies are needed to understand the factors that affect patients' early satisfaction to identify areas of improvement and thus improve HRQoL.

Keywords: Health-related quality of life, Determinants, Satisfaction, Outpatient, Substance dependence

\section{Introduction}

Given the chronic, relapsing nature of substance use disorder (SUD) $[1,2]$ and the negative consequences in various life domains affected by drug use [3], there has been expanding interest in measuring patient-reported

\footnotetext{
* Correspondence: steph_bedes@yahoo.fr

'CSAPA (Health Care Center of Accompaniment and Prevention in Addictology), University Hospital of Nancy, 54000 Nancy, France

${ }^{3}$ EA4360 APEMAC (Health adjustment, measurement and assessment, interdisciplinary approaches) MICS team, University of Lorraine, 54500 Vandoeuvre-lès-Nancy, France

Full list of author information is available at the end of the article
}

outcomes in people with SUDs in recent years. Numerous studies have included health-related quality of life (HRQoL) and quality of life (QoL) assessment as an important clinical and research tool, as an outcome for assessing the health of patients with SUDs and for evaluating drug programs [4-6]. Although QoL and HRQoL are different (QoL is an all-inclusive concept incorporating all factors that impact an individual's life, while HRQoL includes only those factors related to an individual's health), they both aim to capture a patient's subjective perception and assessment of his or her health

(c) The Author(s). 2020 Open Access This article is distributed under the terms of the Creative Commons Attribution 4.0 International License (http://creativecommons.org/licenses/by/4.0/), which permits unrestricted use, distribution, and 
and well-being [7, 8]. Currently, there is evidence that QoL will improve as a function of treatment and recovery in patients with SUDs [9]. Moreover, it has been suggested that QoL should be assessed and reported regularly by clinicians from the beginning of addiction treatment to support evaluations of the recovery progress and decision making with regard to continuing care [10].

Among individuals with SUDs, HRQoL is generally poorer than that of the general population and as low as that of individuals with other chronic diseases or serious psychiatric disorders [11-13]. Several sociodemographic and clinical variables have been studied as predictors of baseline QoL among patients suffering from SUD [14, 15]. The findings are somewhat inconsistent and difficult to interpret because of differences in methodologies, instruments and populations [16]. Overall, male gender, younger age, higher education and being employed are consistently associated with better QoL scores [17, 18]. Inversely, suffering from physical and mental comorbidities altered QoL [19, 20]. Regarding the main SUDspecific characteristics, the severity of dependence is constantly associated with poorer functioning in nearly all QoL domains [21], whereas the duration of addiction, drinking patterns and prior treatments are not [22]. It has also been noted that opiate dependence impaired QoL more than alcohol dependence did [23]. Only a few studies have focused on factors associated with HRQoL improvement among the SUD population. Although the literature has shown that specialized SUD treatment enhanced QoL for dependent patients [9], divergent findings have been reported regarding the predictors of substantial improvements in HRQoL [24]. Indeed, some studies provided evidence that QoL improved with abstinence [25], whereas others showed that there was no correlation between a reduction in substance use and HRQoL [26]. In addition, a published study found that sociodemographic and clinical factors, such as marital status, income and somatic or psychological comorbidities, explained differences in QoL changes between alcohol-dependent twins and their abstinent cotwins [27]. Similarly, the relationship between patients' satisfaction with care and QoL changes has not been clearly established among populations with psychiatric disorders [28]. Patient satisfaction can be defined as an individual's cognitive evaluation of and emotional reaction to his or her health care experience $[29,30]$. Particularly important to the provision of quality addiction services, patient satisfaction has been found to predict better treatment outcomes, including better physical and mental health [31] and psychological improvements [32]. Although many studies have explored HRQoL and SUDs, few have analyzed changes in these scores and determinants of their improvement, and no previously published study has focused on patients' early satisfaction as a factor related to changes in HRQoL.

Thus, this study aimed to a) examine patients' HRQoL changes at a 3-month follow-up and b) identify whether early satisfaction with care predicted a change in HRQoL among outpatients who are starting care for alcohol or opioid dependence.

\section{Methods}

\section{Participants and setting}

This study was based on a longitudinal analysis of data from the SUBstance Users Satisfaction and Quality Of Life (SUBUSQOL) cohort. This is a prospective cohort of outpatients aged over 18 years who began care at French specialized addiction treatment centers and met the Diagnostic and Statistical Manual of Mental Disorders, fourth edition (DSM-IV) [33] criteria for alcohol dependence or opioid dependence (ClinicalTrials.gov ID: NCT02894476). The participants were recruited by clinicians who were certified in addiction pathologies. The treatment wards had multidisciplinary staff, including psychiatrists, psychologists, social workers and specialized nurses. Treatment included individual motivation enhancement, supportive therapy, pharmacotherapy and assessments of somatic and mental health.

\section{Data collection}

Upon entry into the SUBUSQOL study, sociodemographic and clinical data were collected at the time of inclusion (T0) and 3 months after inclusion (T2) through medical interviews and clinical testing. HRQoL and anxiety-depression were assessed with self-reported questionnaires at T0 and T2. Satisfaction was assessed with a self-administered questionnaire to be completed at home 15 days after the first visit (T1). Outpatients who returned the satisfaction with care questionnaire comprised the cohort for the present set of analyses.

\section{Health-related quality of life}

Health-related quality of life was assessed with the Short-Form 12 questionnaire (SF-12), which is a generic 12-item instrument based on the earlier SF-36 [34]. The French version has yielded valid and reliable clinical assessments of self-reported health status among substance users $[35,36]$. The SF-12 covers eight domains: physical functioning, role-physical (that is, role limitations due to physical problems), bodily pain, general health, vitality, social functioning, role-emotional (that is, role limitations due to emotional problems) and mental health. Information from all 12 items is used to calculate a physical health component summary (PCS) and a mental health component summary (MCS). All scores were transformed to a standardized 0-100 score, with higher scores indicating better HRQoL. 


\section{Outpatient satisfaction}

Satisfaction was assessed with the quality of care satisfaction in outpatient consultation questionnaire (EQSC), for which validity and reliability have been previously established [37]. The EQS-C self-report questionnaire includes 27 items assessing 4 dimensions that explore different aspects of care and satisfaction with staff and treatment: contact/appointments (6 items), reception facilities (5 items), waiting time ( 3 items) and consultation with the doctor (13 items). Each item is scored from 0 to 4 , with 4 indicating the greatest level of satisfaction. A "does not apply" category is provided for 13 items related to situations that are not universally relevant. Nonresponses and selection of the "does not apply" category were considered missing data. Scores were computed when at least half of the items in a dimension were completed. The score for each dimension was calculated by summing the items. All scores were transformed to a standardized 0-100 score, with higher scores indicating greater satisfaction. The questionnaire comprised one additional item on intended behavior to consult again that is not in the scoring, as well as sociodemographic data, overall life satisfaction and an open-ended comment field at the end of the questionnaire.

\section{Anxiety and depression}

Anxiety and depression were assessed using the French version of the Hospital Anxiety and Depression Scale (HADS), which yields valid and reliable clinical assessments of depression and anxiety [38]. The HADS is a 14-item self-report questionnaire assessing levels of anxiety and depression with 7 items for each subscale [39]. Each item is scored on a 4-point Likert scale. For each subscale, the score is obtained by summing the respective 7 items (subscale scores range from 0 to 21). Each subscale has three severity ranges based on cut-off scores: 0-7 (noncases), 8-10 (mild severity), and 11-21 (moderate or severe severity) [40].

\section{Sociodemographic and clinical data}

These data included factors that might be related to changes in HRQoL: gender, age, marital status, educational level, occupational status, type of substance dependence, duration of illness, medication introduced, presence of psychiatric and/or somatic comorbidity and origin of the care request. Data related to the physician, including gender, academic qualifications and years of clinical practice, were also noted.

\section{Statistical analysis}

\section{Descriptive and comparative analyses}

Continuous variables were described by the mean or the median, as appropriate, and categorical variables were described by percentages. Student's t-test and Pearson's chi-squared test or Fisher's exact test were used to compare groups.

\section{Bivariate and multivariable analyses}

Prior to data analysis, the structure of the 3 questionnaires (SF12 / 2-dimensional, HADS / 2-dimensional and EQS-C / 4-dimensional) was verified in the study sample using a correspondence analysis. Overall, the results obtained from our study sample were satisfactory. For the SF12, two dimensions were found (eigenvalues (cumulative \%)) $\operatorname{dim}$ 1: 0.50 (81.4\%), and dim 2: 0.18 (92.7\%). For the HADS, two dimensions were also identified $\operatorname{dim}$ 1: 0.43 (45\%) and $\operatorname{dim} 2: 0.22(59.9 \%)$. And for the EQS-C questionnaire, 4 dimensions were identified with $\operatorname{dim}$ 1: 0.47 (37.7\%), $\operatorname{dim} 2: 0.30$ (55\%), dim 3: 0.22 (63.9\%) and dim 4: $0.12(67.8 \%)$.

Linear regression models were performed to determine the variables associated with changes in PCS and MCS scores $(\triangle \mathrm{HRQoL}=\mathrm{HRQoL}$ at 3 months $-\mathrm{HRQoL}$ at baseline). Sociodemographic and clinical factors, the influence of anxiety or depression and the early satisfaction with care score were investigated. Factors with $p$ values $<0.2$ in the unadjusted analysis were candidates for inclusion in the multivariable models. No selection procedure was applied in the multivariable analysis. The correlations between the variables retained in the models were also tested. Assumptions (e.g., normality, linearity) were verified before making comparisons between groups and building regression models. Analyses were performed using SAS 9.4 (SAS Inst., Cary, NC, USA).

\section{Results}

\section{Patient characteristics}

A total of 136 patients assessed their satisfaction with care (79.1\%), out of 172 patients included in the cohort at baseline (Fig. 1). The sociodemographic and clinical characteristics of the patients are presented separately in Table 1 according to whether the EQS-C was answered. Most of the EQS-C responders were male (82.4\%), with a mean age of 39.1 years $(\mathrm{SD}=10.5)$. More than onethird of the patients were married (38.9\%), more than half were unemployed (60.3\%), and a minority reported having a high school or university level education (16.3\%). According to the DSM-IV criteria, 52 (38.2\%) patients suffered from alcohol dependence, and 84 patients (61.8\%) suffered from opioid dependence. The mean duration of substance dependence was 14.9 years $(\mathrm{SD}=11.1)$. Almost one-third of the patients $(30.6 \%)$ presented a comorbid Axis I diagnosis. Eleven patients required care while undergoing legally mandated addiction treatment. All of the physicians were currently working with patients with substance dependence, and 100 outpatients were screened by a junior physician (73.5\%). In $43.4 \%$ of all cases, the patient and physician 


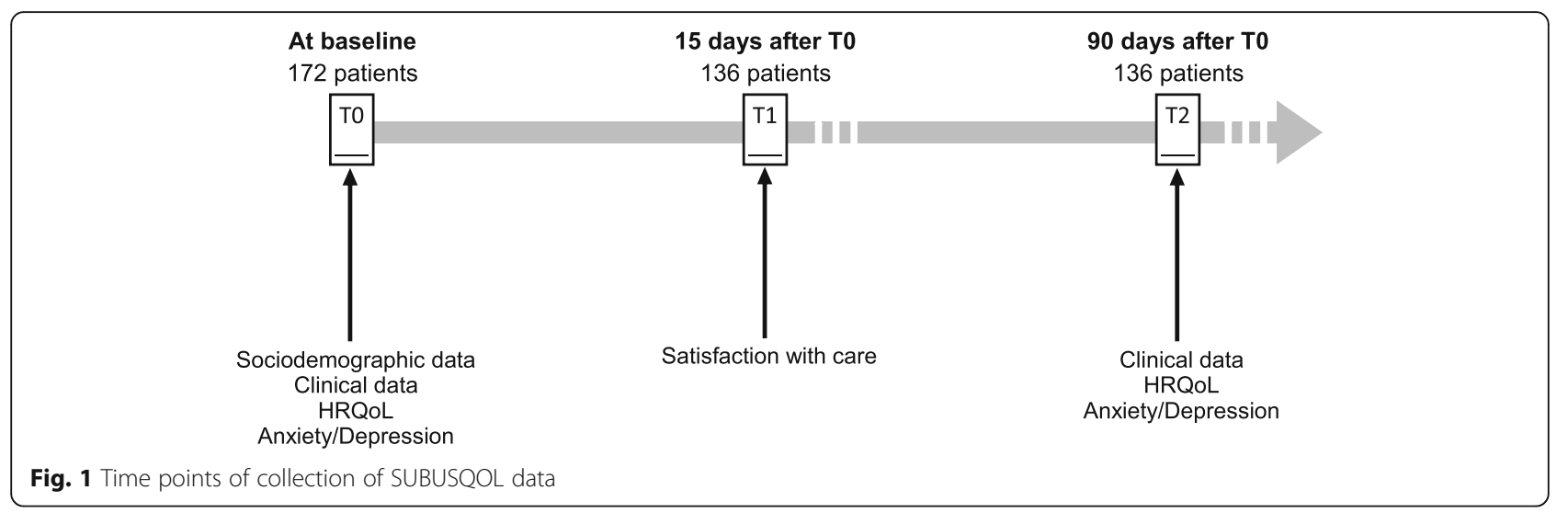

were of the same gender. After 3 months, the average number of medical sessions completed was 7.3 ( $\mathrm{SD}=$ 4.5 ), and a positive change in substance use behavior was observed for $84(63.2 \%)$ outpatients. Patients with opioid dependence $(p=0.01)$ and those who did not have the same gender as their physicians $(p=0.04)$ were significantly more likely to be EQS-C nonresponders; otherwise, the EQS-C nonresponders did not differ from the EQS-C responders in terms of their sociodemographic or clinical characteristics.

\section{SF-12 and HADS scores at baseline and at the 3-month follow-up}

The mean and median PCS, MCS and HADS scores at baseline and at the 3-month period of care are shown in Table 2.

At T0, the mean SF-12 scores were $45.2(\mathrm{SD}=9.0)$ and 36.1 ( $\mathrm{SD}=10.7$ ) for the PCS and MCS domains, respectively. The mean HADS score for the depression subscale was $7.9(\mathrm{SD}=4.1)$, and the mean HADS score for the anxiety subscale was $10.3(\mathrm{SD}=4.5)$. The results did not reveal a significant difference between the EQS-C responders and nonresponders in terms of their HRQoL and HADS scores at baseline. After 3 months, the outpatients who responded to the EQS-C showed a positive change in HRQoL scores. The mean SF-12 MCS and SF-12 PCS changes showed significant positive improvements of $7.2(\mathrm{SD}=12) \quad(p<0.0001)$ and $2.8(\mathrm{SD}=8.9)$ $(p=0.0004)$ points, respectively. The results also showed a positive change in anxiety and depression levels during the first 3 months, with decreases of $2.6(\mathrm{SD}=3.8)(p<$ $0.0001)$ and $2.5 \quad(\mathrm{SD}=3.8) \quad(p<0.0001) \quad$ points, respectively.

\section{Satisfaction scores}

The satisfaction scores are shown in Table 3. The mean overall satisfaction score was $80.8(\mathrm{SD}=15.2)$. The mean satisfaction scores were $80.6(\mathrm{SD}=19.1)$ for "contact/appointments", 79.4 (SD = 16.1) for "reception facilities",
$76.5(\mathrm{SD}=22.6)$ for "waiting time", and $82.5(\mathrm{SD}=16.5)$ for "consultation with the doctor".

Of the 136 EQS-C responders, 119 (87.3\%) intended to consult with the doctor again after the initial consultation. A total of 71 (51.7\%) patients made several comments in the open-ended comment field of the EQS-C. Less than a quarter of these comments were negative, and those pertained to waiting and reception.

\section{Factors associated with HRQoL changes}

The results of the bivariate and multivariable analyses are reported in Table 4. Three variables were associated with significant SF-12 PCS improvement from T0 to T2, with a proportion of variance explained (i.e., $\mathrm{R}^{2}$ ) of 0.47 . Never being married $(\beta=5.5 ; p=0.001)$, being married $(\beta=4.0 ; p=0.02)$ and having a lower SF-12 PCS score at baseline $(\beta=-0.6 ; p<0.0001)$ were associated with a statistically significant increase in the physical domain score at 3 months. Being legally compelled to undergo addiction treatment $(\beta=-5.9 ; p=0.02)$ was associated with a lower PCS score change compared to personal choice. Two variables were associated with significant SF-12 MCS improvement from T0 to T2, with a proportion of explained variance (i.e., $R^{2}$ ) of 0.40 . Significant increases in the mental health domain were observed at 3 months among outpatients with higher early satisfaction with care $(\beta=0.1 ; p=0.02)$ and with lower SF-12 MCS score at baseline $(\beta=-0.7 ; p<0.0001)$.

\section{Discussion}

This study showed low HRQoL at baseline and positive changes in both the physical and mental health domains of HRQoL at the 3-month follow-up among outpatients with substance dependence who were seeking treatment. These results were consistent with previous studies that showed that QoL was low among individuals with SUDs [41-43] and that significant improvements in both the mental and physical dimensions of QoL were found at the three-month follow-up [44-47]. Interestingly, the positive change in the physical 
Table 1 Participant characteristics at baseline (T0)

\begin{tabular}{|c|c|c|c|c|c|}
\hline \multirow[t]{2}{*}{ Characteristics } & \multicolumn{2}{|c|}{$\begin{array}{l}\text { Satisfaction Outpatient responders } \\
N=136\end{array}$} & \multicolumn{2}{|c|}{$\begin{array}{l}\text { Satisfaction Outpatient nonresponders } \\
N=36\end{array}$} & \multirow[t]{2}{*}{$P$-value } \\
\hline & $\mathrm{n}$ & Mean (SD) or \% & $n$ & Mean (SD) or \% & \\
\hline Age (years) & 134 & $39.1(10.5)$ & 35 & $38.1(10.9)$ & 0.6 \\
\hline \multicolumn{6}{|l|}{ Gender } \\
\hline Male & 112 & 82.4 & 30 & 83.3 & \multirow[t]{2}{*}{0.89} \\
\hline Female & 24 & 17.6 & 6 & 16.7 & \\
\hline \multicolumn{6}{|l|}{ Marital status } \\
\hline Never married & 51 & 38.9 & 19 & 52.8 & \multirow[t]{3}{*}{0.13} \\
\hline Married/live with a partner & 51 & 38.9 & 14 & 38.9 & \\
\hline Separated/divorced/widowed & 29 & 22.1 & 3 & 8.3 & \\
\hline \multicolumn{6}{|l|}{ Educational level } \\
\hline Primary school & 16 & 11.9 & 3 & 8.3 & \multirow[t]{3}{*}{0.63} \\
\hline Secondary school & 97 & 71.9 & 25 & 69.4 & \\
\hline High school/university & 22 & 16.3 & 8 & 22.2 & \\
\hline \multicolumn{6}{|l|}{ Living arrangements } \\
\hline Alone & 44 & 32.6 & 12 & 33.3 & \multirow[t]{4}{*}{0.94} \\
\hline Alone with partner and/or children & 59 & 43.7 & 16 & 44.4 & \\
\hline With family or friends & 26 & 19.3 & 6 & 16.7 & \\
\hline Homeless & 6 & 4.4 & 2 & 5.6 & \\
\hline \multicolumn{6}{|l|}{ Occupational status } \\
\hline Unemployed/student & 82 & 60.3 & 20 & 57.1 & \multirow[t]{4}{*}{0.98} \\
\hline Full-time work & 41 & 30.1 & 11 & 31.4 & \\
\hline Part-time work & 7 & 5.1 & 2 & 5.7 & \\
\hline Retired & 6 & 4.4 & 2 & 5.7 & \\
\hline \multicolumn{6}{|l|}{ Type of dependence } \\
\hline Alcohol dependence & 52 & 38.2 & 6 & 16.7 & \multirow[t]{2}{*}{0.01} \\
\hline Opioid dependence & 84 & 61.8 & 30 & 83.3 & \\
\hline Duration of addiction (years) & 136 & $14.9(11.1)$ & 36 & $12.3(8.8)$ & 0.2 \\
\hline Comorbid axis I diagnosis (yes) & 55 & 30.6 & 11 & 40.4 & 0.28 \\
\hline \multicolumn{6}{|l|}{ Origin of the care request } \\
\hline Patient & 100 & 73.5 & 25 & 69.5 & \multirow[t]{3}{*}{0.3} \\
\hline Justice & 11 & 8.1 & 4 & 11.1 & \\
\hline Medical care & 25 & 18.4 & 7 & 19.4 & \\
\hline Patient-physician gender match (yes) & 59 & 43.4 & 9 & 25.0 & 0.04 \\
\hline Medication initiated during the 3-months follow-up (yes) & 53 & 39.6 & 9 & 25.7 & 0.13 \\
\hline Change in substance use behavior at 3 months (yes) & 84 & 63.2 & 18 & 50 & 0.15 \\
\hline Number of medical sessions during the 3-month follow-up & 127 & $7.3(4.5)$ & 33 & $7.5(5.0)$ & 0.21 \\
\hline
\end{tabular}

domain of HRQoL was smaller than the change in the mental domain. Previous authors have suggested that the lack of improvement within the physical health domain might be due to a shortage of time for allowing substantial improvements or to the intractability of some somatic health problems [48]. 
Table 2 Self-reported Health status scores at baseline (T0) and a 3-month follow-up (T2) for EQS-C responders

\begin{tabular}{|c|c|c|}
\hline \multirow[t]{2}{*}{ Self-reported Health status } & \multicolumn{2}{|c|}{ Satisfaction Outpatient responders $N=136$} \\
\hline & $\bar{n}$ & Mean (SD)/ Med* \\
\hline \multicolumn{3}{|l|}{ SF-12 PCS } \\
\hline PCS at baseline & 131 & $45.2(9.0) / 45.8^{*}$ \\
\hline PCS at 3 months & 130 & $48.0(7.9) / 50.6^{*}$ \\
\hline \multicolumn{3}{|l|}{ SF-12 MCS } \\
\hline MCS at baseline & 131 & $36.1(10.7) / 34.5^{*}$ \\
\hline MCS at 3 months & 130 & $43.0(10.2) / 42.9^{*}$ \\
\hline \multicolumn{3}{|l|}{ HADS } \\
\hline Anxiety subscale score at baseline & 128 & $10.3(4.5) / 10^{*}$ \\
\hline Anxiety subscale score at 3 months & 128 & $8.0(4.1) / 8^{*}$ \\
\hline Depression subscale score at baseline & 129 & $7.9(4.1) / 8^{*}$ \\
\hline Depression subscale score at 3 months & 127 & $5.6(3.8) / 5^{*}$ \\
\hline
\end{tabular}

Abbreviations: SD standard deviation, Med* median, SF-12 Short-Form 12, PCS Physical Component Summary, MCS Mental health Component Summary, HADS Hospital Anxiety and Depression Scale

The study enabled us to identify several factors linked to a favorable short-term change in HRQoL. First, the improvement in both psychological and physical HRQoL was more pronounced when the score for each selfreported QoL domain was low. This was somewhat expected as it has previously been shown for patients with SUDs $[49,50]$. In line with previous studies suggesting that the relationships between patient satisfaction and HRQoL were more significant for the mental health domain [51], the most expected finding was that improvement in the mental component of HRQoL was related to early outpatient satisfaction with care. The current study showed that the mean overall satisfaction score was aligned with studies reporting the mean overall satisfaction scores with French outpatients in medical and surgical departments at public teaching hospitals in Paris [37]. Researchers exploring the relationship between satisfaction with care and QoL among patients with serious mental illness have largely reported a positive relationship between the two [52, 53]. Nevertheless, studies investigating the causal nature of this relationship have remained sparse, and thus far, only a few have found a positive association between satisfaction with care and QoL among those patients [28, 54]. Thus, our results might be even more useful for interventions among clinicians to make them more aware of patients who are

Table 3 Outpatient early satisfaction with care (T1)

\begin{tabular}{|c|c|c|}
\hline \multirow[t]{2}{*}{ Satisfaction with care } & \multicolumn{2}{|c|}{ EQS-C responders $N=136$} \\
\hline & $\mathrm{n}$ & Mean (SD) or \% \\
\hline \multicolumn{3}{|l|}{ EQS-C scores } \\
\hline Contact/appointments & 132 & $80.6(19.1)$ \\
\hline Reception facilities & 135 & $79.4(16.1)$ \\
\hline Waiting time & 135 & $76.5(22.6)$ \\
\hline Consultation with the doctor & 135 & $82.5(16.5)$ \\
\hline Overall satisfaction & 136 & $80.8(15.2)$ \\
\hline "I think I will continue attending this department" & 136 & \\
\hline Agree & & 31.6 \\
\hline Fully agree & & 55.7 \\
\hline Comments on the open-ended EQS-C question "What part of our service do you think could be improved?" & 136 & \\
\hline No comment & & 48.0 \\
\hline Positive comment & & 27.2 \\
\hline Negative comment & & 16.1 \\
\hline Mixed comment & & 8.7 \\
\hline
\end{tabular}


Table 4 Predictors of Health-related Quality of Life change from baseline to the 3-month follow-up

\begin{tabular}{|c|c|c|c|c|c|c|c|c|}
\hline \multirow[t]{3}{*}{ Patients characteristics } & \multicolumn{4}{|c|}{$\Delta^{*}$ SF-12 PCS N $=118$} & \multicolumn{4}{|c|}{$\Delta^{*}$ SF-12 MCS N $=123$} \\
\hline & \multicolumn{2}{|c|}{ Bivariate analysis } & \multicolumn{2}{|c|}{$\begin{array}{l}\text { Multivariate analysis } \\
R^{2}=0.47\end{array}$} & \multicolumn{2}{|c|}{ Bivariate analysis } & \multicolumn{2}{|c|}{$\begin{array}{l}\text { Multivariate analysis } \\
R^{2}=0.40\end{array}$} \\
\hline & $\beta /$ Mean & $P$-value & $\beta /$ Mean & $P$-value & $\beta /$ Mean & $P$-value & $\beta /$ Mean & $P$-value \\
\hline Age (years) & -0.02 & 0.84 & & & 0.08 & 0.47 & & \\
\hline Gender & & 0.70 & & & & 0.89 & & \\
\hline Male & 3.0 & & & & 7.3 & & & \\
\hline Female & 2.2 & & & & 6.9 & & & \\
\hline Educational level & & 0.15 & & & & 0.69 & & \\
\hline Primary school & 7.2 & & & & 4.6 & & & \\
\hline Secondary school & 2.1 & & & & 7.5 & & & \\
\hline High school/university & 3.3 & & & & 8.0 & & & \\
\hline Marital status & & 0.01 & & 0.005 & & 0.47 & & \\
\hline Never married & 5.6 & & 5.5 & 0.001 & 5.6 & & & \\
\hline Married/live with a partner & 2.8 & & 4.0 & 0.02 & 8.3 & & & \\
\hline Separated/divorced/widowed & -1.1 & & 0.0 & & 8.6 & & & \\
\hline Occupational status & & 0.4 & & & & 0.78 & & \\
\hline Unemployed & 2.3 & & & & 7.5 & & & \\
\hline Employed & 3.7 & & & & 6.8 & & & \\
\hline Type of dependence & & 0.17 & & & & 0.38 & & \\
\hline Alcohol dependence & 1.4 & & & & 8.4 & & & \\
\hline Opioid dependence & 3.7 & & & & 6.5 & & & \\
\hline Duration of addiction (years) & 0.04 & 0.61 & & & -0.09 & 0.37 & & \\
\hline Origin of the care request & & 0.03 & & 0.014 & & 0.84 & & \\
\hline Patient & 3.3 & & 0.0 & & 7.0 & & & \\
\hline Health practitioner & 3.7 & & 2.1 & 0.2 & 8.5 & & & \\
\hline Justice & -4.9 & & -5.9 & 0.02 & 6.4 & & & \\
\hline Comorbid axis I diagnosis & & 1.0 & & & & 0.09 & & 0.26 \\
\hline Yes & 2.8 & & & & 8.7 & & 0.0 & \\
\hline No & 2.8 & & & & 4.9 & & 2.0 & \\
\hline Medication initiated during the 3-month follow-up & & 0.81 & & & & 0.10 & & \\
\hline Yes & 3.0 & & & & 4.9 & & & \\
\hline No & 2.9 & & & & 8.6 & & & \\
\hline Change in substance use behavior at 3 months & & 0.79 & & & & 0.98 & & \\
\hline Yes & 2.7 & & & & 7.2 & & & \\
\hline No & 3.2 & & & & 7.1 & & & \\
\hline \multicolumn{9}{|l|}{ Self-reported health status at baseline } \\
\hline HADS depression subscale & & 0.05 & & 0.77 & & 0.02 & & 0.14 \\
\hline HADS depression subscale score $<8$ & 0.9 & & 0.0 & & 4.6 & & 0.0 & \\
\hline HADS depression subscale score $\geq 8$ & 4.0 & & -0.4 & & 9.7 & & -3.0 & \\
\hline HADS anxiety subscale & & 0.14 & & & & 0.65 & & \\
\hline HADS anxiety subscale score $<8$ & 1.0 & & & & 6.8 & & & \\
\hline HADS anxiety subscale score $\geq 8$ & 3.5 & & & & 7.9 & & & \\
\hline SF-12 PCS & -0.62 & $<0.0001$ & -0.6 & $<0.0001$ & & & & \\
\hline SF-12 MCS & & & & & -0.67 & $<0.0001$ & -0.7 & $<0.0001$ \\
\hline EQS-C overall satisfaction score & 0.0 & 0.95 & & & 0.17 & 0.01 & 0.1 & 0.02 \\
\hline
\end{tabular}


unsatisfied early in their care. Moreover, if other studies were to confirm our results, then measures targeted at clinicians might be created to improve early satisfaction and increase the QoL change. As half of the items on the outpatient satisfaction questionnaire used are related to the dimension "consultation with the doctor", further research is needed to address the influence of the patient-therapist or therapeutic alliance, the therapist's empathy and the patient-therapist consensus regarding the QoL change, as has been suggested for populations with SUD [55].

Our findings showed that marital status and the origin of the care request were associated with physical HRQoL changes. In our study, never being married appeared to be much more strongly associated with greater improvement in physical HRQoL than being married. This finding was consistent with a previous study on QoL by age group that found greater HRQoL improvement among single participants than among married participants [56]. Being legally compelled to undergo addiction treatment was associated with lower physical HRQoL changes in our sample. Studies investigating coerced drug treatment remain quite limited. However, most of them did not detect significant positive effects of coerced treatment on drug use $[57,58]$. Moreover, some of those studies suggested that coerced treatment could alter self-reported health status $[59,60]$. We could assume that the coercive nature of mandated addiction treatment could offset its early clinical benefits for HRQoL.

Given the low HRQoL among outpatients with substance dependence who seek care, one would intuitively expect an association between changes in substance use behavior and HRQoL improvement. However, the literature has reported mixed findings and has highlighted that improved QoL may not rely upon abstinence or a reduction in substance use [9]. Although previous studies among patients with SUDs have shown that female gender [9] and an absence of psychiatric comorbidities $[16,49]$ were associated with better QoL improvement, our study did not find significant associations between gender or comorbidities and HRQoL changes. The same applies for SUD-specific characteristics, such as duration of addiction or change in substance use behavior. The fact that sociodemographics and SUD-specific characteristics did not predict HRQoL changes does not prove that they are unrelated. The small number of patients included in this study reduced the power; therefore, true relationships between gender, age, comorbidities, and duration of dependence and QoL change might not have been detected.

Our study showed that the baseline HRQoL scores of alcohol- and/or opioid-dependent outpatients were much more impaired than those of the general French population [61] and were lower than those of patients with serious mental disorders [62, 63]. Moreover, the scores in the mental domain were more altered than the scores in the physical domain. These findings are consistent with other studies using the SF-12 or the SF-36 questionnaires to measure HRQoL in patients with SUD [49, 64-66]. The mean age of our patient sample was 38.9 years, and one-fifth of the patients were women, which is consistent with the demographics found in addiction research $[67,68]$. Moreover, the mean duration of substance dependence was consistent with the time taken to establish substance dependence [69]. In line with a previous study [66] and compared with the proportion of French people over 18 years of age who were unemployed and living alone (9 and 30\%, respectively) [70], the high proportion of patients who were unemployed and living alone shows social and familial causes and consequences of substance dependence. Finally, given the prevalence of somatic and mental disorders among substance users and to target patients' needs and improve care engagement, care skills should be provided through several links with primary health care and mental health system [71].

The study has some limitations. The sample cannot be considered as a reflection of all patients with alcohol or opiate dependence seen in routine medical practice because the participants were recruited through specialty treatment services and their satisfaction was assessed at an early stage of care. Less than a quarter of the participants did not complete the outpatient satisfaction questionnaire, which may limit the generalizability of the results. Nonetheless, very few differences in demographic or clinical characteristics and self-reported health status were found between those who completed the outpatient satisfaction with care questionnaire and those who did not.

To our knowledge, this study is the first to assess the effects of early satisfaction with care on early changes in HRQoL among outpatients starting care for alcohol or opioid dependence. Moreover, the EQS-C response rate of $79,1 \%$ demonstrated the patients' willingness to evaluate their own care, a finding that supports patients' interest in measuring their satisfaction with ambulatory care in further studies. Considering the response rate of $51.7 \%$ for the open-ended comment field of the EQS-C, future qualitative interviews might lead to more information regarding how outpatients with substance dependence perceive satisfaction and could determine which factors might affect early satisfaction with care.

Considering the improvement of HRQoL associated with better early satisfaction with care, this issue will be further explored among both patients and clinicians in future studies and in clinical practice to suggest improvements in the early care of these patients. The present study also has several methodological merits. 
First, patient satisfaction was measured shortly after inclusion. Thus, the level of early satisfaction with care that the patients expressed was independent from later improvements in their HRQoL. Our study design also required patients to complete the satisfaction questionnaire at home, thus avoiding a variant of the Hawthorne effect [72]. Moreover, it is important to note that the multivariable models showed an explained variance of 40 and $47 \%$.

\section{Conclusion}

This study confirms the poor HRQoL of outpatients with substance dependence who were starting care at our French specialized addiction treatment centers and their major improvement after 3 months. The longitudinal design enabled us to identify early satisfaction with care as a factor linked to mental HRQoL change at the 3-month follow up. These findings have several implications. Early satisfaction with care among outpatients with substance dependence should be improved because better early satisfaction with care has been related to better HRQoL improvement. The first step should be to assess satisfaction and HRQoL regularly during outpatient follow-up. From a theoretical perspective, the determinants of patients' satisfaction with early care must be better identified to identify areas of improvement. This could help clinicians better target their patients' needs, an action that has been recognized to enhance treatment engagement, care adherence and therapeutic success. Moreover, these findings, if communicated to patients, could enhance their motivation to enter outpatient treatment.

\section{Abbreviations}

DSM IV: Diagnostic and Statistical Manual of Mental Disorders, fourth edition; EQS-C: quality of care satisfaction questionnaire in the outpatients' consultation; HADS: Hospital Anxiety and Depression Scale; HRQoL: Healthrelated quality of life; QoL: Quality of life; SF-12: Short-Form 12 questionnaire; SUBUSQOL: SUBstance Users Satisfaction and Quality Of Life; SUD: Substance use disorders

\section{Acknowledgments}

The authors gratefully acknowledge the study team and all the care workers for their contribution. We are also grateful to SETHS for supporting this work and to CIC-EC-Inserm CIC1433, particularly to Ms. Pierrez for her assistance.

\section{Authors' contributions}

SB-B, RS, and CB designed the study protocol. SV, PDP, OM, GV and LC collected the data used in the current manuscript. CB and IC-U performed the statistical analysis. OM participated in the discussion and writing of the paper. SB-B and CB oversaw the drafting of the manuscript. All authors contributed by reading and critically revising the paper and agree to be accountable for all aspects of the work. All authors read and approved the final manuscript.

\section{Funding}

Nothing declared.

Availability of data and materials

Data will not be shared to protect the participants' anonymity.

\section{Ethics approval and consent to participate}

All procedures performed in studies involving human participants were in accordance with the ethical standards of the institutional and national research committee (Comité National Informatique et Liberté DR-2013-156) and with the 1964 Helsinki Declaration and its later amendments or comparable ethical standards.

Informed consent was obtained from all individual participants included in the study. Consent forms were signed in the presence of a researcher and kept in the main study site file.

\section{Consent for publication}

All authors gave consent for publication.

\section{Competing interests}

Ophélie Muller declares that she has no conflict of interest. Cedric Baumann declares that he has no conflict of interest. Paolo Di Patrizio declares that he has no conflict of interest. Sarah Viennet declares that she has no conflict of interest. Guillaume Vlamynck declares that he has no conflict of interest. Laura Collet declares that she has no conflict of interest. Isabelle Clerc-Urmès declares that she has no conflict of interest. Raymund Schwan declares that he has no conflict of interest. Stéphanie Bourion-Bédès declares that she has no conflicts of interest.

\section{Author details}

${ }^{1}$ CSAPA (Health Care Center of Accompaniment and Prevention in Addictology), University Hospital of Nancy, 54000 Nancy, France. ${ }^{2}$ Unit of Methodology, Data Management and Statistics, University Hospital of Nancy, 54500 Vandoeuvre-lès-Nancy, France. ${ }^{3}$ EA4360 APEMAC (Health adjustment, measurement and assessment, interdisciplinary approaches) MICS team, University of Lorraine, 54500 Vandoeuvre-lès-Nancy, France. ${ }^{4}$ Service médico-psychologique régional, 1, Rue Seulhotte B.P, 1508257073 Metz, France.

Received: 8 July 2019 Accepted: 23 December 2019

Published online: 07 January 2020

References

1. McLellan AT, Lewis DC, O'Brien CP, Kleber HD. Drug dependence, a chronic medical illness: implications for treatment, insurance, and outcomes evaluation. JAMA. 2000;284(13):1689-95.

2. Koob GF, Volkow ND. Neurocircuitry of addiction. Neuropsychopharmacology. 2010;35(1):217-38.

3. Laudet AB. The Case for Considering Quality of Life in Addiction Research and Clinical Practice. Addict Sci Clin Pract. 2011 jul;6(1):44-55.

4. De Maeyer J, Vanderplasschen W, Broekaert E. Quality of life among opiatedependent individuals: a review of the literature. Int J Drug Policy. 2010; 21(5):364-80.

5. Ugochukwu C, Bagot KS, Delaloye S, Pi S, Vien L, Garvey T, et al. The importance of quality of life in patients with alcohol abuse and dependence. Harvard Rev Psychiatr. 2013;21(1):1-17.

6. Picci RL, Oliva F, Zuffranieri M, Vizzuso P, Ostacoli L, Sodano AJ, et al. Quality of life, alcohol detoxification and relapse: is quality of life a predictor of relapse or only a secondary outcome measure? Qual Life Res. 2014;23(10): 2757-67.

7. Torrance GW. Utility approach to measuring health-related quality of life. J Chronic Dis. 1987:40(6):593-600.

8. Karimi M, Brazier J. Health, health-related quality of life, and quality of life: what is the difference? Pharmacoeconomics. 2016;34(7):645-9.

9. Pasareanu AR, Opsal A, Vederhus JK, Kristensen $\varnothing$, Clausen T. Quality of life improved following in-patient substance use disorder treatment. Health Qual Life Outcomes. 2015;13(1):35.

10. McLellan AT, McKay JR, Forman R, Cacciola J, Kemp J. Reconsidering the evaluation of addiction treatment: from retrospective follow-up to concurrent recovery monitoring. Addiction. 2005;100(4):447-58.

11. Morgan TJ, Morgenstern J, Blanchard KA, Labouvie E, Bux DA. Health-related quality of life for adults participating in outpatient substance abuse treatment. Am J Addict. 2003;12(3):198-210.

12. Griffin ML, Bennett HE, Fitzmaurice GM, Hill KP, Provost SE, Weiss RD. Health-related quality of life among prescription opioid-dependent patients: results from a multi-site study. Am J Addict. 2015;24(4):308-14. 
13. Muller AE, Skurtveit S, Clausen T. Many correlates of poor quality of life among substance users entering treatment are not addiction-specific. Health Qual Life Outcomes. 2016;14:39.

14. Foster JH, Powell JE, Marshall EJ, Peters TJ. Quality of life in alcoholdependent subjects: a review. Qual Life Res. 1999;8(3):255-61.

15. Colpaert K, De Maeyer J, Broekaert E, Vanderplasschen W. Impact of addiction severity and psychiatric comorbidity on the quality of life of alcohol-, drug- and dual-dependent persons in residential treatment. Eur Addict Res. 2013;19(4):173-83.

16. Morgan MY, Landron F, Lehert P. New European alcoholism treatment study group. Improvement in quality of life after treatment for alcohol dependence with acamprosate and psychosocial support. Alcohol Clin Exp Res. 2004;28(1):64-77.

17. Foster JH, Peters TJ, Marshall EJ. Quality of life measures and outcome in alcohol-dependent men and women. Alcohol. 2000;22(1):45-52.

18. Donovan D, Mattson ME, Cisler RA, Longabaugh R, Zweben A. Quality of life as an outcome measure in alcoholism treatment research. J Stud Alcohol Suppl. 2005;15:119-39.

19. Bizzarri J, Rucci P, Vallotta A, Girelli M, Scandolari A, Zerbetto E, et al. Dual diagnosis and quality of life in patients in treatment for opioid dependence. Subst Use Misuse. 2005;40(12):1765-76.

20. Günther $\mathrm{O}$, Roick $\mathrm{C}$, Angermeyer MC, König HH. The EQ-5D in alcohol dependent patients: relationships among health-related quality of life, psychopathology and social functioning. Drug Alcohol Depend. 2007;86(23):253-64.

21. Volk RJ, Cantor SB, Steinbauer JR, Cass AR. Alcohol use disorders, consumption patterns, and health-related quality of life of primary care patients. Alcohol Clin Exp Res. 1997;21(5):899-905

22. Millson P, Challacombe L, Villeneuve PJ, Strike CJ, Fischer B, Myers T, et al. Determinants of health-related quality of life of opiate users at entry to lowthreshold methadone programs. Eur Addict Res. 2006;12(2):74-82.

23. Smith KW, Larson MJ. Quality of life assessments by adult substance abusers receiving publicly funded treatment in Massachusetts. Am J Drug Alcohol Abuse. 2003;29(2):323-35.

24. Nosyk B, Guh DP, Sun H, Oviedo-Joekes E, Brissette S, Marsh DC, et al. Health related quality of life trajectories of patients in opioid substitution treatment. Drug Alcohol Depend. 2011;118(2-3):259-64.

25. Kraemer KL, Maisto SA, Conigliaro J, McNeil M, Gordon AJ, Kelley ME. Decreased alcohol consumption in outpatient drinkers is associated with improved quality of life and fewer alcohol-related consequences. J Gen Intern Med. 2002;17(5):382-6.

26. McHugo GJ, Drake RE, Whitley R, Bond GR, Campbell K, Rapp CA, et al. Fidelity outcomes in the National Implementing Evidence-Based Practices Project. Psychiatr Serv. 2007;58(10):1279-84.

27. Romeis JC, Waterman B, Scherrer JF, Goldberg J, Eisen SA, Heath AC, et al. The impact of sociodemographics, comorbidity and symptom recency on health-related quality of life in alcoholics. J Stud Alcohol. 1999;60(5):653-62.

28. Petkari $E$, Pietschnig J. Associations of quality of life with service satisfaction in psychotic patients: a meta-analysis. PLoS One. 2015;10(8):1352-67.

29. Ware JE, Snyder MK, Wright WR, Davies AR. Defining and measuring patient satisfaction with medical care. Eval Program Plann. 1983;6(3-4):247-63.

30. Urden LD. Patient satisfaction measurement: current issues and implications. Outcomes Manag. 2002;6(3):125-31.

31. Morris ZS, Gannon M. Drug misuse treatment services in Scotland: predicting outcomes. Int J Qual Health Care. 2008;20(4):271-6.

32. Kelly SM, O'Grady KE, Brown BS, Mitchell SG, Schwartz RP. The role of patient satisfaction in methadone treatment. Am J Drug Alcohol Abuse. 2010:36(3):150-4.

33. American Psychiatric Association. Diagnostic and statistical manual of mental disorders, 4th edition, text revision. 4th ed. Washington, DC: American Psychiatric Association; 2000.

34. Gandek B, Ware JE, Aaronson NK, Apolone G, Bjorner JB, Brazier JE, et al. Cross-validation of item selection and scoring for the SF-12 health survey in nine countries: results from the IQOLA project. J Clin Epidemiol. 1998;51(11): 1171-8.

35. Bourion-Bédès $S$, Schwan $R$, Epstein J, Laprevote $V$, Bédès $A$, Bonnet $J$, et al. Combination of classical test theory (CTT) and item response theory (IRT) analysis to study the psychometric properties of the French version of the quality of life enjoyment and satisfaction questionnaire-short form (Q-LESQ-SF). Qual Life Res. 2015;24(2):287-93.
36. Bourion-Bédès $S$, Schwan R, Laprevote $V$, Bédès $A$, Bonnet JL, Baumann C. Differential item functioning (DIF) of SF-12 and Q-LES-Q-SF items among french substance users. Health Qual Life Outcomes. 2015;13:172.

37. Gasquet I, Villeminot S, Estaquio C, Durieux P, Ravaud P, Falissard B. Construction of a questionnaire measuring outpatients' opinion of quality of hospital consultation departments. Health Qual Life Outcomes. 2004;2(1):43.

38. Lépine JP. L'échelle HAD [hospital anxiety and depression scale]. In Guelfi J. D., L'évaluation clinique standardisée en psychiatrie [Standardized Clinical Psychiatric Assessment, Vol. 1], Boulogne: Éd. Médicales Pierre Fabre, 1997; 367-374.

39. Zigmond AS, Snaith RP. The hospital anxiety and depression scale. Acta Psychiatr Scand. 1983;67(6):361-70.

40. Bjelland I, Dahl AA, Haug TT, Neckelmann D. The validity of the hospital anxiety and depression scale: an updated literature review. J Psychosom Res. 2002;52(2):69-77.

41. Garg N, Yates WR, Jones R, Zhou M, Williams S. Effect of gender, treatment site and psychiatric comorbidity on quality of life outcome in substance dependence. Am J Addict. 1999:8(1):44-54.

42. Raisch DW, Campbell HM, Garnand DA, Jones MA, Sather MR, Naik R, et al. Health-related quality of life changes associated with buprenorphine treatment for opioid dependence. Qual Life Res. 2012;21(7):1177-83.

43. Daeppen JB, Faouzi M, Sanchez N, Rahhali N, Bineau S, Bertholet N. Quality of life depends on the drinking pattern in alcohol-dependent patients. Alcohol Alcohol. 2014;49(4):457-65.

44. Eshelman A, Paulson D, Meyer T, Fischer D, Moonka D, Brown K, et al. The influence of alcohol abuse history on the differential, longitudinal patterns of mental and physical quality of life following liver transplantation. Transplant Proc. 2010;42(10):4145-7.

45. Feelemyer JP, Jarlais DCD, Arasteh K, Phillips BW, Hagan H. Changes in quality of life (WHOQOL-BREF) and addiction severity index (ASI) among participants in opioid substitution treatment (OST) in low and middle income countries: an international systematic review. Drug Alcohol Depend. 2014:134:251-8.

46. Mitchell SG, Gryczynski J, Schwartz RP, Myers CP, O'Grady KE, Olsen YK, et al. Changes in quality of life following buprenorphine treatment: relationship with treatment retention and illicit opioid use. J Psychoactive Drugs. 2015; 47(2):149-57.

47. Nosyk B, Bray JW, Wittenberg E, Aden B, Eggman AA, Weiss RD, et al. Short term health-related quality of life improvement during opioid agonist treatment. Drug Alcohol Depend. 2015;157:121-8.

48. Villeneuve PJ, Challacombe L, Strike CJ, Myers T, Fischer B, Shore R, et al. Change in health-related quality of life of opiate users in low-threshold methadone programs. J Subst Abus. 2006;11(2):137-49.

49. Lahmek P, Berlin I, Michel L, Berghout C, Meunier N, Aubin HJ. Determinants of improvement in quality of life of alcohol-dependent patients during an inpatient withdrawal programme. Int J Med Sci. 2009;6(4):160-7.

50. Srivastava S, Bhatia M. Quality of life as an outcome measure in the treatment of alcohol dependence. Ind Psychiatry J. 2013;22(1):41-6.

51. Bamm EL, Rosenbaum P, Wilkins $S$. Is health related quality of life of people living with chronic conditions related to patient satisfaction with care? Disabil Rehabil. 2013;35:766-74.

52. Tierney KR, Kane CF. Promoting wellness and recovery for persons with serious mental illness: a program evaluation. Arch Psychiatr Nurs. 2011;25(2): 77-89.

53. Zendjidjian XY, Baumstarck K, Auquier P, Loundou A, Lançon C, Boyer L. Satisfaction of hospitalized psychiatry patients: why should clinicians care? Patient Prefer Adherence. 2014;8:575-83.

54. Ruggeri M, Nosè M, Bonetto C, Cristofalo D, Lasalvia A, Salvi G, et al. Changes and predictors of change in objective and subjective quality of life: multiwave follow-up study in community psychiatric practice. $\mathrm{Br} J$ Psychiatry. 2005;187:121-30.

55. Cruz-Feliciano MA, Miranda-Díaz C, Fernández-Santos DM, Orobitg-Brenes D, Hunter-Mellado RF, Carrión-González IS. Quality of life improvement in Latinas receiving combined substance use disorders and trauma-specific treatment: a cohort evaluation report. Health Qual Life Outcomes. 2017; 15(1):90.

56. Han KT, Park EC, Kim JH, Kim SJ, Park S. Is marital status associated with quality of life? Health Qual Life Outcomes. 2014;12:109.

57. Urbanoski KA. Coerced addiction treatment: client perspectives and the implications of their neglect. Harm Reduct J. 2010;7:13. 
58. Werb D, Kamarulzaman A, Meacham M, Rafful C, Fisher B, Strathdee S, et al. The effectiveness of compulsory drug treatment: a systematic review. Int J Drug Policy. 2016;28:1-9.

59. Swanson JW, Swartz MS, Elbogen EB, Wagner HR, Burns BJ. Effects of involuntary outpatient commitment on subjective quality of life in persons with severe mental illness. Behav Sci Law. 2003;21(4):473-91.

60. Bright DA, Martire KA. Does coerced treatment of substance-using offenders lead to improvements in substance use and recidivism? A review of the treatment efficacy literature. Aust Psychol. 2013;48(1):69-81.

61. Coste J, Ecosse E, Leplège A, Pouchot J, Perneger T. Le questionnaire MOS SF-36. Manuel de l'utilisateur et guide d'interprétation des scores. Paris 2001: Editions Estem.

62. Vederhus JK, Pripp AH, Clausen T. Quality of life in patients with substance use disorders admitted to detoxification compared with those admitted to hospitals for medical disorders: follow-up results. Subst Abuse. 2016:10:31-7.

63. Adan A, Marquez-Arrico JE, Gilchrist G. Comparison of health-related quality of life among men with different co-existing severe mental disorders in treatment for substance use. Health Qual Life Outcomes. 2017;15(1):209.

64. March JC, Oviedo-Joekes E, Perea-Milla E, Carrasco F. The PEPSA team. Controlled trial of prescribed heroin in the treatment of opioid addiction. J Subst Abus Treat. 2006;31(2):203-11.

65. Astals M, Domingo-Salvany A, Buenaventura CC, Tato J, Vazquez JM, MartínSantos R, et al. Impact of substance dependence and dual diagnosis on the quality of life of heroin users seeking treatment. Subst Use Misuse. 2008; 43(5):612-32.

66. Bourion-Bédès $S$, Schwan R, Di Patrizio P, Vlamynck G, Viennet S, Schvartz M, et al. The effects of patient and physician characteristics on early outpatient satisfaction with substance dependence care: Results of the SUBUSQOL study. Patient Prefer Adherence. 2017; May 8;11:887-96.

67. Palle C, Rattanatray M. 2013. Les centres de soins, d'accompagnement et de prévention an addictologie en 2010 - Situation en 2010 et évolution sur la période 2005-2010 [PDF file]. Retrieved 5 July 2018, from https://www.ofdt. $\mathrm{fr} / \mathrm{BDD} /$ publications/docs/eftxcpw6.pdf

68. Palle C. 2016. Les personnes accueillies dans les CSAPA - Situation en 2014 et évolution depuis 2007 [PDF file]. Retrieved 5 July 2018, from https:// www.ofdt.fr/BDD/publications/docs/eftxcpw6.pdf

69. Ponizovsky AM, Grinshpoon A. Quality of life among heroin users on buprenorphine versus methadone maintenance. Am J Drug Alcohol Abuse. 2007:33(5):631-42.

70. Volant S. 2017. France, social portrait Edition 2017. Consulté 6 juillet 2018, à l'adresse https://www.ofdt.fr/BDD/publications/docs/eftxcpw6.pdf

71. Carrà G, Scioli R, Monti MC, Marinoni A. Severity profiles of substanceabusing patients in Italian community addiction facilities: influence of psychiatric concurrent disorders. Eur Addict Res. 2006;12(2):96-101.

72. Trujols J, Iraurgi I, Oviedo-Joekes E, Guàrdia-Olmos J. A critical analysis of user satisfaction surveys in addiction services: opioid maintenance treatment as a representative case study. Patient Preference and Adherence. 2014;8:107-17.

\section{Publisher's Note}

Springer Nature remains neutral with regard to jurisdictional claims in published maps and institutional affiliations.

Ready to submit your research? Choose BMC and benefit from:
- fast, convenient online submission
- thorough peer review by experienced researchers in your field
- rapid publication on acceptance
- support for research data, including large and complex data types
- gold Open Access which fosters wider collaboration and increased citations
- maximum visibility for your research: over 100M website views per year
At BMC, research is always in progress.
Learn more biomedcentral.com/submissions

